\title{
Informing Clients through Information Communication Technology in Health Care Systems
}

\author{
V. Vishwa Mohan \\ Dept of Library \& Information \\ Science \\ Osmania University, \\ Hyderabad, India
}

drvvm321@yahoo.com

\author{
Vahideh Zarea Gavgani \\ Tabriz University of Medicine. \\ Iran \\ and Osmania University, \\ Hyderabad, India
}

\begin{abstract}
Information Communication Technology (ICT) has revolutionized the world communication order. People can be informed in more effective, efficient and convenient ways. Access to media has percolated to the grassroots. In spite of all such remarkable developments, whether ICT facilitates Science communication is a billion dollar question. Though information is freely and widely available by virtue of ICT, yet, there are areas where Science communication through ICT still needs to be developed to deliver critical information to the needy.

Objectives: The objectives of the study are to find out: whether patients and care givers have perception of their information needs? What sources of information they usually consult?

What type of channels/media they possess to access the information? What sources the patients and care givers prefer to consult? Whether in the opinion of the patients and their care givers, the ICTs are effective in delivering the critical information.

Methodology: An exploratory survey was conducted. A semi-structured interview was employed to collect data from a group of 188 patients and care givers in the hospitals and clinics in Hyderabad (India).

Results and conclusion: The study determined the patients' and care givers' preferences for technologies in keeping informed. It also brought to light the limitations and usefulness of ICTs in Science communication in general and medical information in particular.
\end{abstract}

Keywords: health information, patient information needs, science communication, user preferences

Material published as part of this publication, either on-line or in print, is copyrighted by the Informing Science Institute. Permission to make digital or paper copy of part or all of these works for personal or classroom use is granted without fee provided that the copies are not made or distributed for profit or commercial advantage AND that copies 1) bear this notice in full and 2) give the full citation on the first page. It is permissible to abstract these works so long as cred it is given. To copy in all other cases or to republish or to post on a server or to redistribute to lists requires specific permission and payment of a fee. Contact Publisher@InformingScience.org to request redistribution permission.

\section{Introduction}

Information Technology, particularly, the Information Communication Technology (ICT), has revolutionized the world communication order. People can be informed in more effective, efficient and convenient ways. Access to media has percolated to the grassroots. Even in developing countries like India, peo- 
ple, who are little above the poverty-line, use mobile phones. Television and radio sets are common even in the households in slum areas. News, entertainment, educational and awareness generation programmes are within their reach and affordability.

In spite of all such remarkable developments, whether ICT facilitates Science communication is a billion dollar question. Though information is freely and widely available by virtue of ICT, yet, there are areas where Science communication through ICT still needs to be developed to deliver critical information to the needy. The survey conducted by Vishwa Mohan (1995) revealed that some of the sample mentioned that they are very much frightened and confused by the T.V. announcements on AIDs. It shows that information communicated through mass media sometimes gives rise to confusion and phobia.

However, lack of medical knowledge and proliferation of health information make patients misinformed. It neither ensures the patient safety nor improves patient peace of mind. Nowadays, the information age encounters with new diseases and new patients such as "Information Syndrome" (Gavgani \& Mohan, 2008) and "Cyberchondriac, a person who imagines they have a particular disease because their symptoms match those listed on an Internet health site" (Cybercondriac, 2007).

Roli Srivastava (2008) writes that search engines on the Internet are making I T-driven, new age patients not only better informed and inquis itive about the ir medical condition but many times even belligerent. "Most doctors agree that equations with tech-savvy patients have changed... There is a rift between the patient community and doctors. While it is a good sign that patients are well informed but most of the time it is ending in confrontation with the doctors," says Dr M Veera Prasad of Care Hospital (quoted by Srivastava, 2008). Describing them as 'e-patients', Dr $P$ Vinay Kumar, surgical gastroenterologist with Apollo Hospitals, says (quoted by Srivastava, 2008) this fairly young section of patients often steps into clinics with a "preconceived idea about their diagnosis and treatment options." Most of the times, the e-patient becomes very confident of what he has learnt on the net and questions the doctor accordingly. "One of my colleagues ended up telling a patient's attendants, you seemed to have learnt or want to learn in half-an-hour what we took ten years to do," Dr Vinay Kumar recollects.

In the present days, patients prefer to have information about their health and partic ipate in decision making regarding the ir health problems. Basically, patients trust in their doctor to get information about the ir health condition and problems. At the same time they also consult many other sources of information such as Nurses, Internet, friends, and others who have suffered earlier from similar disease or health problem. Amidst so many sources which are more effective and preferred ones in the view of the patients and care givers? If this is found out, delivery of critical health information can be made as per the preferences of the information seekers. As a matter of fact, patients usually trust in the ir doctor as the right and first preferred source of information. But, doctors usually give oral information to their patients. In this connection, literature shows that mouth-to-ear information communication [i.e. the oral information] is not sufficient. Kemper and Metler (2002) state that "the way doctors and patients exchange information generally mouth-to-ear - is often inefficient, incomplete, and outmoded". In addition, Schnider (2002) states that "patients forget more than three-fourths of information after leaving the doctors room". Besides, doctors do not have so much time to give detailed information to clarify all the doubts of the patients and make sure that they understand the delivered information. This calls for employing auxiliary and supplementary information communication tools in doctor-patient relationship.

In a patient-centred health care system, patient as a bonafide member of the system has to participate in decision making process. Patients should be provided with access to necessary information sources including their health records to obtain the required information. In this connection Information Communication Technologies have changed the communication order from face-to- 
face to telecommunication facilities viz. telephony, Internet, etc. Though, so many communication facilities are existing, preferences of the clientele and availability of the facilities are considerable aspects in choosing the right channels and tools in informing the clients. Especially, in the areas such as Medicine, where more personalized information needs to be disseminated, mass media and similar ICT tools may not prove to be effective tools.

The two years research work on the "Role of medical librarians in Information Therapy, the study of problems and prospects in India and Iran" as the $\mathrm{PhD}$ thesis of Vahideh Zarea Gavgani and seeing the condition and situation of Information Therapy Service to the patients through the libraries gave us the idea to find out Whether in the opinion of the patients/care givers, the selected ICT tools (for the study) are effective in delivering the critical information?

In the developing countries like India where there are 22 regional languages, off icially recognized, and more than 1,600+ dialects (CIA, 2008) with the rate of illiteracy as high as about $35.1 \%$ even after 60 years of independence, it will be very difficult to ensure effective communication of latest developments and concepts in any field for which the regional languages find dearth of vocabulary.

It is in order to find out that in the opinion of the patients and their care givers, which ICTs tools are effective in delivering the critical information required by them, a survey of the patients and care givers is carried out, particularly, in the context of WHO's programme of Health for all by 2020 that has an implication on communication of right information to the right patient at the right time of need to actively partic ipate in the process of health decision-making.

\section{Objective of the Study}

The study aims to find out:

1. Whether patients have perception of their information needs?

2. What sources of information they usually consult?

3. What type of channels/media they possess to access information?

4. What sources the patients and care givers prefer to consult?

5. Whether in the opinion of the patients/care givers, the selected ICT tools (for the study) are effective in de livering the critical information?

\section{Scope of the Study}

The Clientele of the Library and Information centres related to Health Care System include the physicians, nurses, caregivers, pharmacists, pathologists, radiologists, patients, care givers, etc. The above categories of clientele have diverse information needs, hence, the study focuses on informing patients and the ir care givers, usually their family members, friends or relatives who attend the patients. The study covers the geographical area of Hyderabad City, which is a representative metropolitan city where there are people hailing from different regions and linguistic backgrounds. As the city contains super-specialty, multi-specialty and large-scale corporate hospitals, people from different parts of the country including rural and urban areas and also from other countries do come to these hospitals for treatment. Therefore, Hyderabad is selected as the representative city of a developing country. With regard to the ICT tools, the study conf ines itself to email, telephones, mobile-phones, CD-ROMs, and Short Message Service (SMS) as these are more personalized tools/means for delivering health/medical information to the patients and their care givers. 


\section{Methodology}

The study primarily aims at ascertaining, whether in the opinion of the patients and the care givers, the selected ICT tools (for the study) are effective in de livering the critical information? To explore the above, an exploratory survey method is employed to carry out the study. As the universe of patients and their care givers is not well defined due to the very fact that there is no system of enrolment of different types of patients and their care givers. For instance, there will be out-patients, patients at the clinics, and the care givers who will be attending the patients, for whom there will not be an official record or register that gives complete details. In other words, since there is no sampling frame, a stratified accidental sample of 200 patients and care givers from different strata such as literate and illiterate groups, rural and urban groups, higher income, Middle income and lower income groups, were selected for the study. Out of the selected 200 cases in the sample, 188 have responded to the interview. For an exploratory survey interview method proves to be more appropriate. Moreover, Questionnaire method will not be suitable for illiterate respondents and patients who may not be in a condition to fill in the questionnaires. Therefore, a semi-structured interview method was employed to collect data from the respondents.

\section{Analysis}

The rate of response i.e. $94 \%$ of the sample is very much considerable as it reveals interesting aspects of the use of ICT in Science communication in general and communication of health information to the patients and care givers in particular. The data collected through the semistructured interview is analyzed and presented below:

\section{Composition of the Sample}

The group of respondents belong to the following categories: literates $64.9 \%$ and illiterates $35.1 \%$; urban residents $54.78 \%$ and rural $45.22 \%$; higher income group $32.45 \%$, middle income $36.7 \%$, and lower income $30.85 \%$. The response from lower and higher income groups was little less, it is therefore, out of 200 selected samples, 188 only responded otherwise the percentage of respondents in lower and higher income categories also would have been almost equal to middle income group.

\section{Whether Patients Have Perception of their Information Needs}

Of the responding patients and care givers $95.7 \%$ have expressed that they wish to have information about the ir health and health problems. This response shows that there is a substantial perception of information needs on the part of the patients and care givers. It also indicates that there is an evolutional change or shift in the attitude of the members of the modern community towards information and the ir right to information. It is interesting to note that the conventional doctor-centred medicine is being replaced with patient-centred medicine in India. Unlike in the past, where doctors seldom used to inform the patients about the ir health condition or problems and involve them in health decision making, they used to inform the family members in stead of the patient himself or herself, the present practice is that the patient is informed and involved. Some of the respondents from the remaining $4.3 \%$ of sample have said 'no' and some neither said 'yes' nor 'no' to the question on whether they wish to seek information about the ir health problems. It is ascertained from the interview that those who said 'no' prefer not to know about their health problems. Out of these $4.3 \%$ respondents, 6 were illiterates and 2 were literates and of the literates there is also a respondent belonging to higher income group. This respondent who is a care giver clearly said that the information about the health condition of the nearer and dearer would create severe anxiety and phobia. For the past three months I am unable to eat and sleep. 


\section{Information Needs of the Patients and Care givers}

Most of the respondents expressed that their needs are related to what is the exact disease or health problem they have. What is the latest and cheapest treatment available? Some of the patients have expressed their need as to whether the doctor's suggestion to undergo the treatment is valid or invalid. It is because some of the patients have developed wrong notions that some of the doctors may give unnecessary treatment for commercial gains. In addition to these all most all patients have expressed that they need information about the availability, appointment of the doctor. Very few about $14 \%$ of the respondents expressed their desire to know the side effects of the medication/drugs, alternative medicine, symptoms and post-therapeutic care.

\section{Patients' Sources of Information about their Health}

The response relating to the sources that patients consult for information about their health has clearly shown that $100 \%$ of them seek information from the doctors, but $59.6 \%$ of the respondents obtain information only through doctors, they do not consult other sources. Whereas, it is interesting to note that $40.4 \%$ of them also consult other sources in addition to the doctors. Interestingly $19.1 \%$ have stated that they also get information from friends. $2.1 \%$ consult library for information. The pie diagram in Figure 1 shows the data relating to other sources.
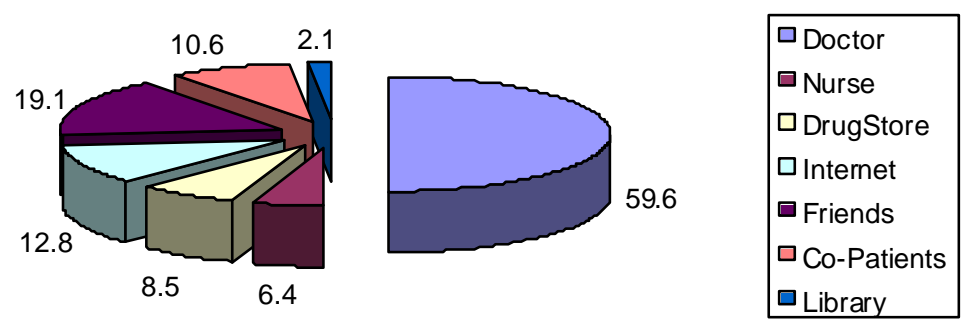

\section{Figure 1 the sources of information that patients prefer to consult}

As Figure 1 shows, $12.8 \%$ of the patients go to the Internet for health information. While $10.6 \%$ seek information from the co-patients and $8.5 \%$ consult with pharmacists in drugstores and a less percentage 6.4, most of them are illiterates, consult nurses for information. From the interview it is learnt that these patients and care givers are scared to seek additional information or clarifications repeatedly from the doctors. They prefer to seek clarifications from the nurses who attend the patients.

The above data shows the patient's attitude toward their concerned doctors, as the reliable sources of information. In addition 'friends' as another source of information is used more than Internet. Unlike the high rate of people turning to Internet for health information in USA (Fox, 2005, Rainie \& Fox, 2000), in India the Internet stays in the third place among the sources of information for patients. Of late there are news items in the newspapers relating to the changing behaviour of the patients due to information they obtain through the Net. Doctors complain that they have problems with such patients. In a report entitled Dr Internet Panacea for all ills, Srivastav (2008) quotes Dr. M Veeraprasad from Care Hospital as saying "there is a rift between the patient community and doctors. While it is a good sign that patients are well informed but most of the times it is ending in confrontation with the doctor." This he has reported in the context of how information obtained from Internet is causing the confrontation. 
Conversation with co-patients is expressed as very valuable source of information by considerable percentage of the respondents from the $10.6 \%$ respondents who seek information from the co-patients.

In fact, consulting the co-patients is not desirable as the information obtained may not be accurate or authentic, as a result it gives rise to circulation of wrong information. Though $10.6 \%$ have stated that they seek information from co-patients, on uncertainty of information obtained from co-patients, all the respondents have answered the question. Of them $48.9 \%$ of the respondents are of the opinion that 'this information is uncertain.' However, a greater percentage i.e. $51.1 \%$ of the respondents endorsed that it may not be uncertain. It shows that they believe in the information provided by the co-patients. Some of them have expressed that "an old patient is better than a new doctor." As a matter of fact, patients felt relieved when they shared information, pain, suffering or experience among themselves.

\section{Means Patients use to Access the Information}

The respondents were asked to provide information about the means they use or posses to access information. Their response is presented below in the bar diagram in Figure 2.

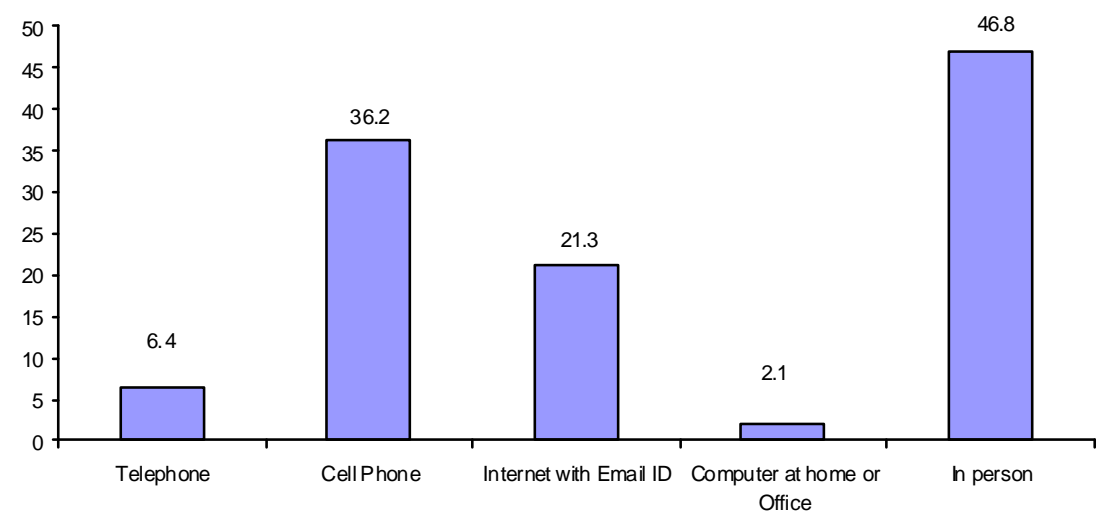

Figure 2 the means patients use to access or receive the information

When it comes to health information almost $100 \%$ of the respondents stated that they go to doctors in person and seek information. However, it is $46.8 \%$ of the respondents who have exclusively stated that they seek information 'in person' from the doctors. Whereas, the others also seek information by employing I T devices or facilities such as telephones, mobile/cell-phones, email, computer at home or at office. It is interesting to note that the doctors and the hospitals have started providing information through emails to the patients. This shows that the trend is changing in seeking information from the hospitals and doctors regarding the availability of the doctors, seeking clarifications relating to the dosage of medic ine, and other aspects. These days the health care systems are providing information to the patients and care givers over phones, mobile/cell-phones, etc. However, very few have stated that they are provided with some edocuments through which they can get their required information. The e-documents are consulted by them by use of computers at their homes or office. But the percentage of these people is very less. These services are not provided to everyone. For instance, in the clinics, all the patients are not given the contact number of the doctor, only few privileged would have the privilege. It is also the same case with the specialists in corporate hospitals. However, the general enquiry number is provided to everyone. 


\section{Patients' Preference of Media}

When the patients were asked about their preference of the means through which they desire to have information, they responded as shown in Figure 3.

46.8

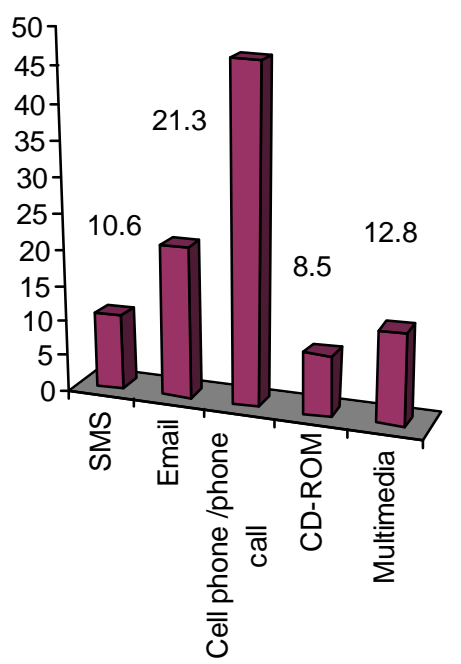

Figure3. Patients' preference in receiving health information

The highest percentage of the respondents that is $46.8 \%$ stated that they prefer to get information through the cell-phone by ranking cell-phones as number one preferred channel. Next to cellphone it is email, ranked second by $21.3 \%$ and the least is CD-ROM. In fact, some of the respondents have emphatically stated that they prefer to have information through their email only. Through the interview it is explored that some of the people do not wish to incur even single call charge on cell-phones, in many a case, even if they wish to contact someone they give missed calls. As emails are almost free and large amounts of information can be delivered over emails, people prefer to use emails. But, on the other hand the illiterates in general and computer illiterates in particular have problems in using the above mentioned tools. They did not rank any thing excepting the cell-phone, by four respondents who possess cell-phone.

\section{SMS as the Rapid Means}

SMS can be considered as a very powerful, cheap and rapid means of communication in the present days. But, are the patients able to understand the SMS, is a question to be verified. As mentioned in the beginning of this paper, India is a country with diverse regional languages with multiple variants and dialects with considerable rate of illiteracy, application of I T tools may not be appropriate in all the situations. Particularly, SMS will not be useful in providing large amounts of information. It can be used for alert services and also informing the patients about the appointments with the doctors. But, do all the patients can understand the messages sent through SMS, which will be usually in English, because presently, the SMS through Cell-phones have English script only. To the question on whether the patients and care givers understand the message sent through SMS. It is hardly 55.3\% said 'yes' whereas about $34 \%$ said 'no'.

\section{SMS in the mother tongue}

Assuming that SMS in English might be the obstacle for science communication, a question as to whether SMS in the mother tongue would be preferable. Only $31.9 \%$ said 'yes', whereas, $46.8 \%$ 
said 'no', it is because all of the illiterates and some of literate respondents who belong to the present generation stated that they cannot read the message even in their regional language, that is, their mother tongue. Some expressed that following the technical terms in the regional languages are very difficult to understand. At the same time there are chances of mistaking or misunderstanding the medical terms. Some of these respondents said, in view of this SMS in English is always better. When a particular patient was interviewed she directly said that when the medical terms are translated into regional language, the unfamiliar equivalents might violate the very purpose of communication. She even said that these words may not be found in the regional language dictionaries, as most of them are not comprehensive and exhaustive. And they rarely contain technical terms. Therefore, she said, "I prefer to get the message in its English and common form rather than its alternative and equivalent forms in the regional language." This shows that the medical language is preferred by people in spite of the complexity existed in its nature. From the above data it is very clear that the percentage of respondents who said 'no' is more than the percentage of the respondents who said 'yes'. It means that people do not prefer the medical messages to be sent through SMS in general and in mother tongue in particular.

\section{Other Alternatives}

To an open-ended question on 'what other media or channels they prefer?' Some of the rural and literate respondents said that Health information can be provided through newspapers. In certain cases, some of the rural respondents said that the media is creating havoc. Especially, when information about the spread of HIV-infection through razors in the barbershops and blood transfusion in the hospitals, they became scared to go to barbershops. Some of them said, they started becoming suspicious about the ir spouse who were recently underwent blood transfusion. The news about the out-break of bird-flu, Dengue, etc. created a scare among the people. This shows that information dissemination through mass media may also create confusion in the community for want of complete and clear information.

\section{Conclusion}

The majority of respondents expressed that they wish to obtain information about the ir health and health problems. This is an indicator of an evolutional change/shift in community's attitude towards information and the ir right to information.

The significant finding of the study is that a considerable number of people in countries like India still lag behind in the use of ICT for better communication. This indicates that there is need for awareness generation in general and education in particular. People need to be educated they should be in a position to read and right and understand the latest concepts and developments. It is not sufficient if the media is extended to all nooks and corners of a nation along with it the impartation of the skills for better utilization of the media is very essential. And basic knowledge and education are essential in the present day society. It is very interesting to note that a good number of respondents did not even prefer to have information through SMS in the ir regional language. It means some of them are so illiterate they cannot even read and write in the ir own mother tongue or regional medium. Further, there is also a factor of the regional media not containing the required vocabulary to communicate the idea, particularly the concepts in the technical fields like medicine. All these problems need to be addressed in the present context, especially when we desire health for all by 2020 . 


\section{References}

CIA (Central Intelligence Agency). (2008). The world fact book. India. Retrieved March 2008 from https://www.cia.gov/library/publications/the-world-factbook/geos/in.html

Cybercondriac. (2007). Wordspy. Retrieved January 24, 2008 from http://www.wordspy.com/words/cyberchondriac.asp

Fox, S. (2005, May 17). Health Information Online. Pew Internet \& A merican Life Project: Online Life Report. Retrieved September 2006 from http://www.pewinternet.org/PPF/r/156/report display.asp

Gavgani, V.Z., \& Mohan, V. V. (2008). Application of web 2.0 tools in medical librarianship to support med icine 2.0. Webology, 5(1), Article 53. Available at http://www.webology.ir/2008/v5n 1/a53.html

Kemper, D. W., \& Mettler M. (2002). Information therapy: Prescribing the right information to the right person at the right time. Managed Care Quarterly, 10(4).

Mohan, V. V. (1995). Community information and the library in the developing society: A state-of-the art and prognostic study with particular reference to rural Andhra Pradesh. Unpublished thes is submitted for Ph.D. to Os mani University Hyderabad, p. 274.

Rainie, L. \& Fox, S. (2000, November 26). The online health care revolution: How the Web helps Americans take better care of themselves. Pew Internet \& A merican Life Project: Online Life Report. Retrieved September 2006 fro $\mathrm{m}$ http://www.pewinternet.org/Reports/2000/The-On line-Health-Care$\underline{\text { Revolution.aspx }}$

Schnider, S. (2002). Information therapy answers the institute of medicines' harsh report. Managed Care Quarterly, 10(1),7-10.

Srivastava, R. (2008, January 13). Dr Internet panacea for all ills. Times of India (Hyderabad).(Front Page). Available at http://www.epaper.timesofindia.co m/Repository/getimage.d ll?path=TOIH/2008/01/13/1/Img/pg001 6 $\underline{0 . p n g}$

\section{Biographies}

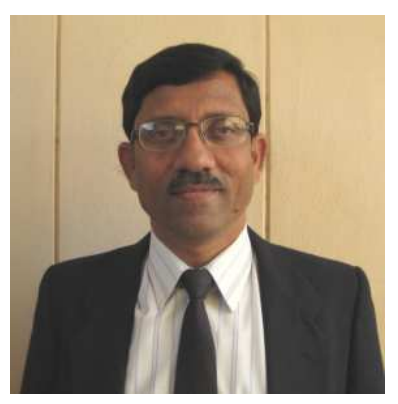

Dr V. Vishwa Mohan, M.A., MLISc, Ph. D. (in Library and Information Science ), is presently Professor and Chairman, Board of Studies in the Department of Library and Information Science, Osmania University Hyderabad, India. He was born in the year 1958. He was head of the Department of Library and Information Science for two terms, Vice President and General Secretary of Indian Association of Teachers of Library and Information science. He has published over 60 research papers in the Indian and international journals and conference proceedings, three books and edited four books. He has produced three Ph.Ds and twelve M.Phils.

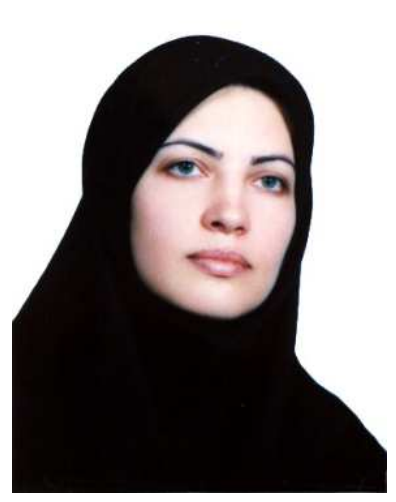

Ms Vahideh Zarae Gavgani is a $\mathrm{PhD}$ research scholar in Library and Information Science at Osmania University Hyderabad, India. She has worked as Medical Librarian, and Library director in Tabriz University of Medical Science and Education in Iran. She has also contributed in the education of Medical Library and Information Science as part time teacher in the same University. She has written about 20 research papers in national and international journals. She also published 3 books and translated 1 book in Persian. Presently she is on study leave from Tabriz University of Medical Science and Education, Iran. 